\title{
ECG précoce de péricardite aiguë : le signe de Spodick
}

\section{Early ECG of acute pericarditis: Spodick's sign}

\section{Tourdias ・ V. Hostyn}

Reçu le 29 août 2013 ; accepté le 28 octobre 2013

(C) SFMU et Springer-Verlag France 2013

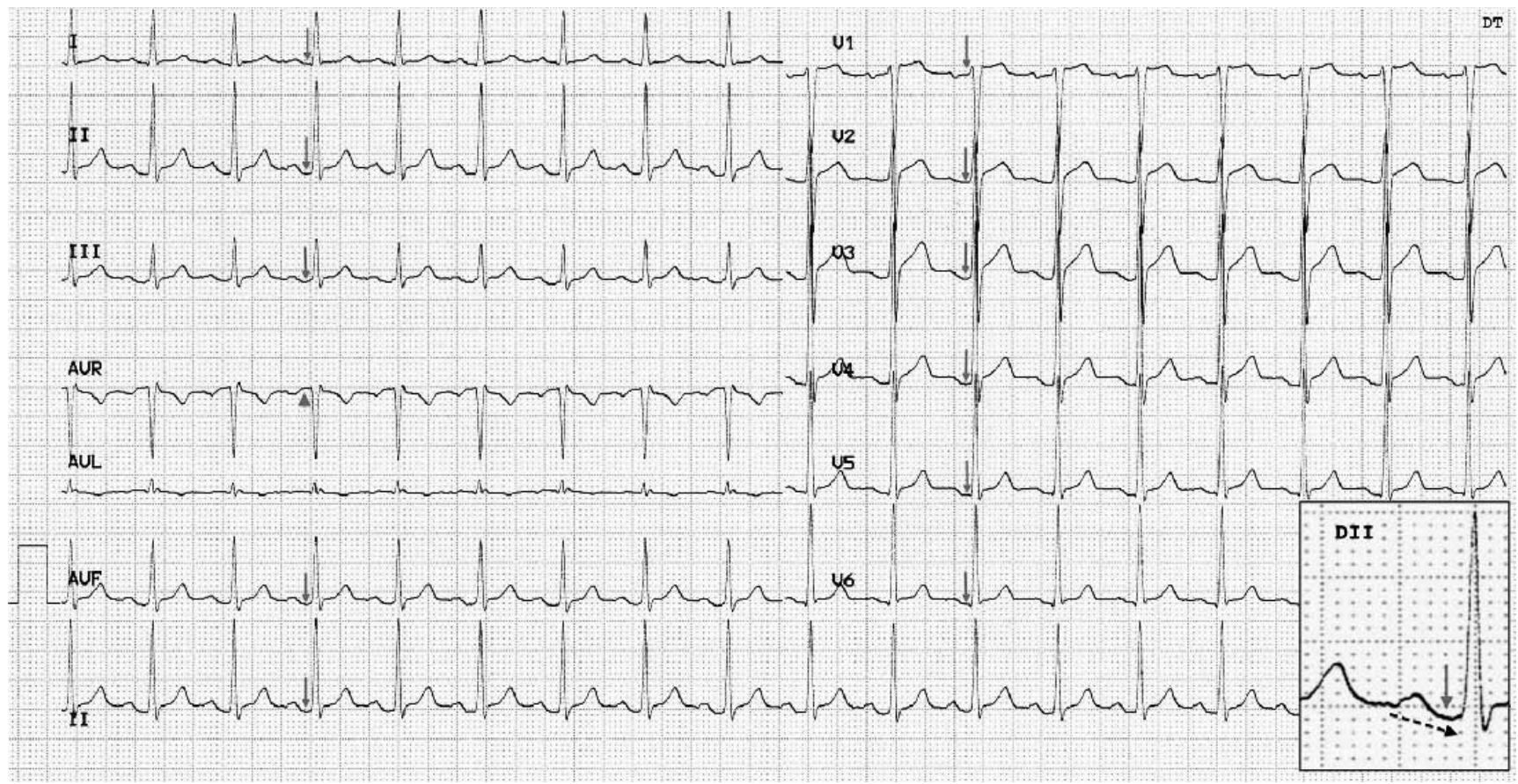

Fig. 1 Signe de Spodick en faveur du diagnostic de péricardite aiguë débutante : sous-décalage du segment PR diffus, descendant et supérieur à $0,8 \mathrm{~mm}$ dans au moins une dérivation (cf. dérivation DII) avec sus-décalage réciproque en VR (tête de flèche)

Un patient de 40 ans consulte aux urgences dix heures après le début brutal d'une intense douleur rétrosternale augmentant à l'inspiration profonde et évoluant dans un contexte de fébricule. Son ECG inscrit des modifications classiques du segment PR au cours d'une péricardite aiguë : sous-décalage franc ( $\geq 1 \mathrm{~mm}$ en DII et V3), d'aspect descendant et concave vers le haut dans toutes les dérivations sauf au niveau de VR où il existe un sus-décalage de $1 \mathrm{~mm}$ (Fig. 1). Par ailleurs, il n'existe pas d'élévation significative du segment ST par rapport à la ligne T-P. Lors d'une péricardite aiguë, un sousdécalage diffus du segment PR (ou PQ), excepté en VR et

\section{Tourdias $(\bowtie) \cdot$ V. Hostyn}

Service d'accueil des urgences - Smur, Centre hospitalier Sud

Gironde, rue Paul Langevin, F-33210 Langon, France

e-mail : tourdiasdamien@yahoo.fr parfois en V1, correspond à un courant de lésion auriculaire témoignant de l'inflammation sous-épicardique au niveau des oreillettes [1]. Cet aspect électrique, aussi connu sous le nom de signe de Spodick, est un signe très évocateur de péricardite aiguë présent dans environ $80 \%$ des cas [1]. Ce signe précoce peut précéder les modifications du segment ST et donc être le seul signe électrocardiographique initial en faveur du diagnostic [2].

\section{Références}

1. Spodick DH (1973) Diagnostic electrocardiographic sequences in acute pericarditis: significance of PR segment and PR vector changes. Circulation 48:575-80

2. Baljepally R, Spodick DH (1998) PR-Segment deviation as the initial electrocardiographic response in acute pericarditis. Am J Cardiol 81:1505-6 